\title{
Once Bitten, Thrice Wise: The Varying Effects of Victimization on Routine Activities and Risk Management
}

\author{
J. Michael Vecchio \\ Loyola University Chicago, jvecchio@luc.edu
}

Follow this and additional works at: https://ecommons.luc.edu/criminaljustice_facpubs

Part of the Criminology Commons, Criminology and Criminal Justice Commons, and the Social Control, Law, Crime, and Deviance Commons

Author Manuscript

This is a pre-publication author manuscript of the final, published article.

\section{Recommended Citation}

Vecchio, J. Michael. Once Bitten, Thrice Wise: The Varying Effects of Victimization on Routine Activities and Risk Management. Deviant Behavior, 34, 3: 169-190, 2013. Retrieved from Loyola eCommons, Criminal Justice \& Criminology: Faculty Publications \& Other Works, http://dx.doi.org/10.1080/

01639625.2012 .726167

This Article is brought to you for free and open access by the Faculty Publications and Other Works by Department at Loyola eCommons. It has been accepted for inclusion in Criminal Justice \& Criminology: Faculty Publications \& Other Works by an authorized administrator of Loyola eCommons. For more information, please contact ecommons@luc.edu. c) (†) $\ominus$

This work is licensed under a Creative Commons Attribution-Noncommercial-No Derivative Works 3.0 License. (c) Taylor \& Francis, 2013. 
Once bitten, thrice wise: The varying effects of victimization on routine activities and risk management

\author{
J. Michael Vecchio \\ University of Missouri-St. Louis \\ St. Louis, Missouri, USA
}

*An earlier version of the paper was presented at the 2010 Midwestern Criminal Justice Association annual meeting in Chicago, IL. The author would like to sincerely thank Jody Miller, T.J. Taylor, Finn Esbensen, as well as the editor and anonymous reviewer for their helpful comments and advice on earlier drafts of the manuscript. Direct correspondence to J. Michael Vecchio, Department of Criminology \& Criminal Justice, University of Missouri-St. Louis, 324 Lucas Hall, St. Louis, MO 63121, USA. Phone: 314-516-5025. Fax: 314-516-5048. E-mail: jmvecchio@mail.umsl.edu.

Author Bio:

J. MICHAEL VECCHIO is a doctoral candidate in the Department of Criminology \& Criminal Justice at the University of Missouri-St. Louis. His research interests include youth violence and victimization, youth gangs, responses to victimization, and crime prevention.

Citation:

Vecchio, J. Michael. 2013. Once bitten, thrice wise: The varying effects of victimization on routine activities and risk management. Deviant Behavior 34(3): 169-190.

DOI: $10.1080 / 01639625.2012 .726167$ 
Once bitten, thrice wise: The varying effects of victimization on routine activities and risk management

\begin{abstract}
While the relationship between offending and victimization is well established, less is understood about what contributes to the varied effects of victimization on future behavior. Drawing on qualitative interviews from a sample of at-risk men, the study explores recognized and unrecognized effects of victimization on subsequent behavior and management of lifestyle risks both within and across narratives. Findings demonstrate a range of perceived effects on behavior and risk management, with the presence or absence of substantive effects related to whether the event was both severe and directly attributable to involvement in at-risk behavior. Consequences for the victimization-termination hypothesis are discussed.
\end{abstract}


Considerable criminological research has demonstrated that victims and offenders are not opposing sides of the crime equation (Esbensen and Huizinga 1991); rather, the risk and likelihood of individual victimization is elevated and best predicted by involvement in offending and other illicit behavior (Gottfredson 1984; Jensen and Brownfield 1986; Lauritsen and Laub 2007; Sampson and Lauritsen 1990). This increased risk and prevalence is commonly related to the increased amount of time that individuals spend in situations with other motivated offenders and an absence of capable guardians (Cohen and Felson 1979; Hindelang et al. 1978; Jensen and Brownfield 1986). Research has further identified that the individuals who are particularly at-risk for victimization are those involved in substance use and street offending lifestyles (Anderson 1994; 1999; Biernacki 1986; Decker and Van Winkle 1996; Jacobs 2000; Jacques and Wright 2008; Sutherland 1937; Waldorf 1973).

As victimization is commonly interpreted as an unpleasant and often traumatic experience, it is expected that victims would elect to subsequently modify their behavior or lifestyle to mitigate future victimization risk. ${ }^{1}$ Nevertheless, victimization experiences have been found to have widely disparate effects on individuals' subsequent behavior. The effects of victimization have included no subsequent behavioral changes (Averdijk 2010; Hindelang et al. 1978; Skogan 1981; Skogan and Maxfield 1981), subtle changes to mitigate the risks of sustained behavior (Averdijk 2010; 2011; Ferraro 1995; Hindelang et al. 1978), and substantial changes in behavior (e.g., change in thinking about behavior and lifestyle as well as temporary or permanent cessation of at-risk behavior) to more fully alleviate victimization risk (Adler 1993; Averdijk 2011; Cusson and Pinsonneault 1986; Decker and Lauritsen 2002; Jacques and Wright 2008; Ousey et al. 2011). However, less attention has been afforded to exploring what it is about

\footnotetext{
${ }^{1}$ See Hindelang and colleagues' (1978) once bitten, twice shy thesis - which assumes some degree of victim rationality.
} 
victimization as well as how individuals perceive these experiences that produce varying effects on subsequent behavior.

The current study examines the nature and influence of victimization on subsequent behavior and management of the hazards of at-risk lifestyles. More specifically, the present study examines 1) the nature of victimization within an at-risk sample; 2) whether victimization experiences are related to perceived behavioral change and whether victimization is identified as the catalyst for any such change; and 3) whether the nature of victimization - victimization type and attribution of victimization to individual at-risk behavior - can help illuminate why victimization produces varying effects on subsequent behavior within and across individuals. To do this, the study draws on qualitative interviews with a group of at-risk men involved in an outpatient alcohol and drug rehabilitation center in a major Midwestern metropolitan area.

\section{RELATED LITERATURE}

\section{Victim and Offender Overlap}

While victims historically garnered less scholastic inspection than offenders, emphasis on the victim population and their experiences is now commonplace. What has been identified is that victims and offenders are often demographically, culturally, and behaviorally similar (Lauritsen and Laub 2007). ${ }^{2}$ This finding has been consistent across time, place, and subgroups (Lauritsen and Laub 2007) and has been upheld by both quantitative (Esbensen and Huizinga 1991; Jensen and Brownfield 1986; Lauritsen et al. 1991) and qualitative analysis (Anderson 1999; Decker and Van Winkle 1996; Jacobs and Wright 2006).

The development of routine activities and lifestyles perspectives have particularly aided in the study of the victim and offender overlap. Hindelang and colleagues' (1978) lifestyles

\footnotetext{
${ }^{2}$ These demographic, cultural, and behavioral similarities are more applicable for some forms of violence than others - notable exceptions include child abuse and domestic violence (see Fagan and Browne 1994; Widom 1989a; 1989b).
} 
perspective stipulates that daily routine behavior - specifically vocational and leisure activities form a lifestyle which directly influences victimization propensity. Cohen and Felson’s (1979) routine activities theory identifies that crimes occur at the convergence of a motivated offender, a suitable target, and the absence of capable guardianship. These perspectives have been largely upheld by subsequent research, demonstrating that victimization risk and occurrence is significantly influenced by how often individuals’ lifestyles bring them into situations devoid of capable guardianship with greater proximity to motivated offenders (Garofalo 1979; Jensen and Brownfield 1986; Miethe and Meier 1994).

\section{At-Risk Groups}

As individual risk of victimization increases with the amount of time spent around motivated offenders, some of the most at-risk individuals are those involved in illicit drug use and street offending. Prior research on varying at-risk populations - including drug users, dealers, and smugglers, gang members, robbers, and persistent thieves - has consistently found an intensified risk and occurrence of victimization (Adler 1993; Anderson 1999; Biernacki 1986; Decker and Van Winkle 1996; Jacobs 1999; 2000; Jacques and Wright 2008; Shover 1996; Sutherland 1937; Waldorf 1973) as well as a variety of factors contributing to this risk. Those involved in a life as party lifestyle (Shover 1996) often carry money, illicit substances, or weapons on their person (Adler 1993; Decker and Van Winkle 1996; Jacobs 1999; 2000; Shover 1996). Simply having these highly desirable items on your person should increase target attractiveness and victimization risk (Clarke 1999; Cohen and Felson 1979).

Further amplifying victimization risk among street offenders is a general reluctance or inability to report crimes to the police. This restricted ability to report victimization experiences to the police is tied implicitly to a fear of self-incrimination in illegal activities (Jacobs 2000; 
Lauritsen et al. 1991; Sampson and Lauritsen 1990), a general mistrust in police (Anderson 1999; Rosenfeld et al. 2003), as well as a desire to resolve the crime personally through retaliatory action (Decker and Van Winkle 1996; Jacobs 2000; Jacobs and Wright 2006). Absent the help of formal guardians, individuals involved in a substance using and street offending lifestyle must be more cognizant of risks and attempt to manage them accordingly (see Jacques and Reynald 2012).

\section{Effects of Victimization}

As a generally undesirable and unpleasant experience, victimization has been found to produce varying short and long-term changes in perceptions of crime as well as future behavior (Ferraro 1995; Hindelang et al. 1978). The influence of victimization on the future behavior of individuals commonly manifests in subtle practical changes in behavior. These subtle changes are designed to mitigate risks of sustained behavior and at-risk lifestyles. These subtle changes frequently include the application of risk minimization and avoidance techniques such as defensive weapon carrying, travelling in groups, as well as other changes in patterns of illicit and leisure activities (Averdijk 2010; 2011; Decker and Van Winkle 1996; Ferraro 1995; Hindelang et al. 1978; Jacobs and Wright 2006; Jacques and Reynald 2012). The widespread application of subtle risk alleviating behaviors is consistent with Hindelang and colleagues’ (1978) assertion that the effects of crime are most commonly subtle adjustments in behavior; "rather than making substantial change in what they do, people tend to change the ways in which they do things” [emphasis in original] (Hindelang et al. 1978:224).

Other research has demonstrated that victimization can serve as an event which can directly facilitate more substantial change in behavior. Indicative of this is the work of Decker and Lauritsen (2002), where the most frequently cited motivation for gang members to leave 
their gang was exposure to violence and victimization. Other research has similarly found that victimization experiences serve as a motivator for substantial change in individual lifestyle and the decision to terminate involvement in specific illicit behaviors. These changes notably include cessation of involvement in gang activities, robbery, and drug dealing and trafficking (Adler 1993; Cusson and Pinsonneault 1986; Decker and Van Winkle 1996; Jacques and Wright 2008; Ousey et al. 2011). For these individuals, victimization appears to serve as a shock or harsh reminder of the dangers of sustained involvement in at-risk behavior and lifestyles.

Research has also demonstrated that victimization does not necessarily lead to subsequent changes in behavior (Averdijk 2010; Hindelang et al. 1978; Skogan 1981; Skogan and Maxfield 1981). Studies which have relied on general population samples (notably the British Crime Survey and the National Crime Survey/National Crime Victimization Survey) have emphasized that many victims perceive their victimization(s) to be a relatively minor experience(s) which have little to no impact on their daily routines and lifestyle (Averdijk 2010; 2011; Mayhew 1993; Skogan 1981; Skogan and Maxfield 1981). Other research which has identified no change in behavior subsequent to victimization has drawn on accounts from active male offenders. This active offender research has further identified a pattern whereby a victimization experience, whether minor or severe, may foster an individual's desire to alleviate some of the loss and discomfort of the episode through one or more acts of retaliatory violence (Anderson 1999; Jacobs 1999; 2000; Jacobs and Wright 2006). While retaliatory violence is well documented in active offender samples, research has also demonstrated that males actively involved in illicit lifestyles are often less likely to emphasis the salience of victimization experiences (Hindelang et al. 1978; Melde 2009; Van Dijk 1986). This reluctance can be influenced by the belief that active denial of the salience of victimization experiences on future behavior will act as an illustration of 
nerve in the face of danger and will further promote a masculine and tough demeanor (Anderson 1994; 1999).

While it is clear that victimization experiences can produce a range of perceived and actual effects on subsequent behavior, it is less clear what it is that contributes to the varied nature of its effects on behavior. It is possible that variability of victimization, in regard to its nature and context, may contribute to the varying effects victimization experiences have on subsequent behavior (Averdijk 2010; 2011; Jacques and Wright 2008). The effects of victimization on subsequent behavior may also vary based on victimization severity as well as whether individuals perceive a victimization experience to be a product of their own at-risk behavior or whether it is thought to be an unrelated and unavoidable consequence of life within a high-risk community (Averdijk 2010; Brezina et al. 2009; Jacques and Wright 2008; Mayhew 1993).

\section{THE CURRENT STUDY}

Given the at-risk nature of substance users and street offenders, the goal of the present study is to explore the nature of victimization within the sample as well as closely examine whether individuals perceived victimization experiences to have influenced how they subsequently behaved and navigated the risks of their lifestyle. For those who discuss change in behavior or the management of risk, the study emphasizes whether individuals identify victimization as the catalyst of change and whether changes are specifically related to the nature of the victimization incident. This research uses retrospective ethnographic data from a sample of at-risk men on probation and parole in a substance use rehabilitation program. The varied offending and victimization experiences of the present sample of at-risk men provide an opportunity to explore the perceived effect of victimizations' on subsequent behavior as well as 
provide insight into the varied nature of responses through detailed narrative accounts.

\section{METHODOLOGY}

Data for this study come from a project on drug use, crime, and the challenges to recovery and reintegration. All interviews were conducted with clients participating in a mandatory drug treatment center in a major Midwestern metropolitan area. The two mandatory treatment programs taught by the center (Recovery and Diversionary) provide treatment services for men on probation and parole that have been identified as having problems with substance use. Clients in both programs were overwhelmingly African-American with a small minority of white and other races or ethnicities. Interviews were conducted in the spring of 2010, were voluntary and confidential in nature, and respondents were given a small gift card for their participation.

The project sample included in-depth interviews with 36 male clients - split evenly across the two programs. Consistent with the demographics of both programs, the sample includes 34 African-American and two white subjects. Within the full sample, respondents ranged in age from 19 to 50 years, with a mean age of 32. The Recovery program is designed for males post release from incarceration. Clients are typically referred to the Recovery program through their parole officer to help retain sobriety during reentry. Recovery clients in the sample ranged in age from 22 to 48, with an average age of 34. Center administrators asserted that only about a quarter of Recovery program clients were incarcerated on substance related offenses. The Diversionary program is an intervention/diversionary program designed for mostly high-risk and/or gang-affiliated younger adult males. Diversionary clients in the sample ranged in age from 19 to 50, with an average age of 30. Clients in this program are on state supervision, but typically have not been previously incarcerated. Unlike the Recovery program, center 
administrators believed that Diversionary clients are more likely to have been recently active users and have been arrested for substance related offenses.

While all individuals involved in the mandatory drug treatment center had identified problems with substance use, the vast majority of respondents also discussed some prior involvement in illicit drug sales (32 respondents ${ }^{3}$ ). Aside from substance use and sales, the majority of clients also discussed involvement in as well as arrest for an assortment of other atrisk and street offending behavior (21 respondents). This included gang affiliation (four respondents) as well as engagement in or arrest for assault (10 respondents), robbery (five respondents), theft (four respondents), burglary (four respondents), weapons violations (nine respondents), and nonsupport (child support) (two respondents). Contrary to prior research's focus on the effects of victimization on specific active at-risk populations (e.g., drug dealers, gang members, and robbers), the assorted nature of offending experiences in the present at-risk sample affords a unique opportunity to explore and inform what contributes to the varied nature of victimization's perceived effects on individual behavior.

\section{Sampling}

The study design involved the project's principal investigator explaining the purpose and nature of the project at the end of every Recovery and Diversionary group session during a single week period. Over the course of the two month data collection period, two approaches were used to solicit volunteers. Volunteers were initially recruited by the principal investigator then contacted by a field researcher who scheduled a time to visit the center to conduct the interview. Later, field researchers visited the center on designated days and solicited volunteers at the end of group counseling sessions - often with the help of program counselors and administrators.

\footnotetext{
${ }^{3}$ Only Curtis, Eddie, and Orlando indicated having never had any involvement in drug sales throughout their lives.
} 
Interviews were typically conducted on the same day and if more clients volunteered than field researchers were present, random selection was used to select interviewees. ${ }^{4}$

All interviews were conducted in private offices within the center - away from treatment staff and other clients - and were audio-recorded, transcribed, and assigned a pseudonym. The interviews took approximately an hour and a half to complete and used a semi-structured field guide of open-ended questions. This technique allowed field researchers to ask probing followup questions to elicit greater detail in respondent answers as well as reveal and resolve any discontinuity or incongruence within narratives (see Miller 2011). For the purpose of this study, subjects were asked (1) whether they had ever experienced any problems or issues while buying or selling drugs as well as (2) whether they were ever the victim of a crime or violence. ${ }^{5}$ For each question, those that answered affirmatively were asked to discuss their victimization in greater detail. The men were then asked whether they believed the experience was related to their behavior or drug use, whether they perceived it to change or influence their subsequent behavior, as well as how they avoided problems and conflicts. Subjects were then asked if there were any other times they were the victim of a crime or violence and, if affirmative, were again asked the aforementioned follow-up questions. The goal of using these open-ended questions was to provide subjects with numerous opportunities to discuss a variety of problems, issues, and victimizations as well as provide equally wide latitude for subjects to discuss any changes in behavior following the experience(s).

\footnotetext{
${ }^{4}$ If more individuals volunteered than field researchers were present, a simple random selection process was used. Any unselected volunteers were told they were welcome to volunteer on another day researchers were present. However, the use of this practice was uncommon as there was typically the same number of volunteers as researchers present.

${ }^{5}$ In three interviews (Gary, Lamont, and Sean), respondents were specifically asked to describe their "most recent or most memorable conflict or problem." These were the only three instances in which subjects were explicitly prompted for their 'most recent or most memorable' problem or issue.
} 
The present methodological approach and comparative convenience sampling strategy has inherent strengths and limitations. As complete life-histories were not a viable part of the study (see Roberts and Horney 2010), the study is unable to explore the effect of every unique victimization an individual experienced as well as any cumulative effect of victimizations on behavior. Furthermore, the study draws from individual narrative accounts of whether victimizations were perceived to subsequently influence future behavior. Perceptions are inherently subjective, but are as important to the way people ascribe meaning to experiences and view their social world as other objective events and conditions (see Agnew 2006; Miller 2011). While the methodological approach used in the present study does not produce generalizable findings, the qualitative approach used is well-suited for producing rich narrative accounts of individual experiences. These accounts provide evidence of victimization's perceived influence, or lack there of, on subsequent behavior and are useful for informing theoretical insight (see Miller 2005; 2011). Rigorous examination of the narratives allowed for inductive identification of thematic patterns and processes underlying victimization and responses to them at the situational level as well as exploration of the perceived meanings attributed to these experiences.

Before starting data analysis, all narrative data were merged into two data files specific to victimization and the perceived effects of victimization. Systematic comparisons were conducted and identified no notable differences - specific to age, victimization, and responses to victimization experiences - between men in the Recovery and Diversionary groups, thus the present study treats them as a single sample of at-risk men. Using inductive analytic techniques, including line-by-line open and focused coding, emergent themes were identified then tested, refined, or rejected using modified grounded theory techniques (Charmez 2006; Glaser and Strauss 1967; Miller 2011) and domain analysis (Spradley 1979). Domain analysis was 
conducted using the universal semantic relationship of strict inclusion to identify all forms of victimization (i.e., personal, property, and vicarious) and behavioral responses to victimization (e.g., application of risk minimization techniques, application of risk avoidance techniques, change in abstract thinking about at-risk behavior and/or lifestyle, and temporary or permanent cessation of at-risk behavior and/or lifestyle). Central to the inductive process, the search for deviant cases, discontinuities within and across narratives, and disconfirming evidence of identified patterns and themes was employed throughout the analysis (Charmaz 2006; Miller 2011; Silverman 2006). The concepts and narratives provided herein typify the most common patterns within and across accounts. Simple tabulations are included to further demonstrate the strength of patterns and provide the transparency necessary for readers to assess the finding and conclusions (Miller 2005).

\section{FINDINGS}

Consistent with research on other substance using and street offending populations (see Adler 1993; Decker and Van Winkle 1996; Jacobs 2000; Jacobs and Wright 2006; Waldorf 1973), just fewer than $90 \%$ of the sample discussed some form of personal, property, or significant vicarious victimization (i.e., the violent victimization of a close friend or family member). ${ }^{6}$ Given the extent of exposure to victimization within the sample, the goal of the present study is to examine the perceived effects of victimization on subsequent behavior and management of risk. To begin, the nature of victimization across the narratives is discussed, including the type of victimization as well as the context in which it occurred. Then, any reported behavioral responses to victimization are discussed, including how future victimizations were

\footnotetext{
${ }^{6}$ While 31 respondents reported some victimization experience, Bobby was excluded from subsequent analysis. While he noted being a victim, he did not discuss the victimization incident and was not asked any of the appropriate follow-up questions. The lack of information about Bobby's victimization and its potential effects on behavior warranted case exclusion.
} 
avoided and whether changes were consciously recognized. Finally, the perceived effects of victimization are compared across the two most commonly discussed forms of victimization (robbery and being shot or fired at). In doing so, the present study provides evidence of how victimization experiences exude particular influence on subsequent behavior and management of risk when individuals attribute the experience to their at-risk behavior or lifestyle.

\section{Victimization}

Respondents varied in the number of victimization experiences discussed during the interviews; the majority (17 or 57\%) of respondents discussed two or more victimizations while the remainder (13 or $43 \%$ ) of respondents only discussed one victimization experience. ${ }^{7}$ The findings in Table 1 also indicate that the at-risk sample of men discussed exposure to victimization in a variety of forms. The vast majority of victimized men discussed having been the victim of a personal crime (25 or $83 \%$ ). Robbery victimization, either attempted or successful, was experienced by 21 men (70\%) and was by far the most common form of crime victimization discussed. A number of respondents reported being shot (7 or 23\%) and shot at (6 or $20 \%$ ) while a few others reported being assaulted or having been in fights (3 or 10\%).

\section{--INSERT TABLE 1 ABOUT HERE--}

Though discussed less frequently, a number of the men also reported property victimization (7 or 23\%). Several men indicated having been "ripped off” or having been sold bad or fake drugs (4 or 13\%). Several others indicated being given counterfeit money in exchange for drugs or had people steal their drugs without the threat of force (4 or 13\%). One final form of victimization that emerged throughout the interviews was significant vicarious

\footnotetext{
${ }^{7}$ The extent of victimizations discussed was dependent on how much information the respondent felt comfortable divulging as well as how rigorously the field researcher probed for multiple victimization experiences. Only three individuals (Barry, Franklin, and Isaac) were asked only once if they were the victim of crime or violence. All other victimized respondents were probed to discuss at least two incidences, if applicable.
} 
victimization, with a few men having discussed a loss or near loss of a close friend or family member when asked about their experiences with victimization (3 or 10\%).

As indicated, the most prominent form of victimization discussed in this sample was robbery. While not exclusively, these victimizations occurred most commonly in the context of selling drugs. Gary explained: "Well, it was when I was selling. I leaned over the car to do the sale; the guy popped it out of my hand then stuck a gun to my head.” Stanley said, "A man said he had 50 bucks, and I went into the house behind him and he like kind of held me up with a knife up to my neck.” Lamont reiterated this kind of experience while selling: "guy said he wants to spend 100 dollars... and when I put it in his hand...[h]e brandished a weapon and said 'Aight thanks'.”

Robbery over the course of a drug exchange was not exclusively a threat to dealers, but also occurred while or immediately after respondents were trying to purchase drugs for personal use. Orlando described his drive into a public housing project looking for drugs "and uh went and pulled over to some brothers, I didn’t even really know ‘em, but...they stand out there like they're selling. Before I had the chance to even, you know, look, I had a gun up under my jaw, and, 'Give me the money! Give me the money before I shoot ya!' and shit like that. 'Okay, here ya go." William indicated how he was robbed following a successful drug purchase: “I got robbed... he hit me with the bottom of the gun and took everything...I just bought some and stuff, and was gonna go put it up, and they came out the gangway on me...when I looked over he hit me with the gun...I guess he was just watchin,' watchin' from a distance [at the drug transaction].”

For others, robbery victimization occurred in different contexts, but was routinely believed to have been motivated by the perpetrator's need for drugs. In describing his 
victimization, Walter said, “this man, I guess he wanted some drugs or whatever, and ain't have no money. And uhm, he grabbed my partna, and put the gun up to 'em. And dude had the gun on me.” Eric similarly explained:

People...used to watch me and see when I used to go to work in the morning 'cause you know how that drug, how the little crack fiends, how they be out during the day or in the morning when you go get up and go to work, and they watch you when you come in and come back in to work. And they be trying to study my bank payday, and every Friday they used to try to rob me...'cause they know I had been cashed my check, and I had my money on me, so they see me come from work, trying to take me on the elevator, or ride up the elevator with me, and try to rob me.

Another common personal victimization discussed was being shot or fired at. Three situational contexts were prevalent in respondents’ accounts: gang activity, being in the wrong place at the wrong time, and drug dealing. Consistent with the gang context, Carter said his assailant was “targeting anybody he just thought was a gangbanger.” Stanley similarly noted that his being shot in the head during a highway shooting was “over some gang stuff.” As for being in the wrong place at the wrong time, Frank explained how he "was indulgin' in alcohol at a party" and he "just happen to be at the wrong place at the wrong time" when he was shot. Anton was 14 years old when he was shot in the head over what he thought were his clothes and his gold teeth fronts, but "come to find out that was, I was out there at the wrong time. They said it was meant for somebody else.” Terrance experienced something similar when he was “shot...in the back of the head and in my um, right arm with a 12 gauge shotgun...It was supposedly a mistaken identity.”

The final context in which respondents were shot or fired at was while dealing drugs. Reggie noted an interaction with a buyer which turned into a violent encounter, "he going in his pocket, like looking off, like counting his money, he come up with a gun, you know, I just break on him though, so he shot all the shots at me, ain't none hit me though.” Kenny also indicated he 
had been shot a number of times while dealing, but that he "was kinda slinging and gang banging" at the time. He noted that being in a gang and dealing drugs was "like double the threat. 'Cause you got guys want, want to do stuff to you, just because of where you stay at [gang affiliation]. And then you got guy want to do something to you 'cause of what you doing [dealing drugs]." Perhaps the most indicative of the drug dealer's risk of violent victimization was Victor’s rationalization over why he had been shot over ten times: “Guys, you know, [think] 'he a target, he’s selling dope, he got that money, he got that drugs, we seen him, we need that dope, we need that money, so let's rob him.' That's what they did. They robbed me and shot me up.”

A few subjects also reported being the victim of a simple or aggravated assault. Isaac attributed getting his throat slit at a club to just being "in the field. Just by bein' in that lifestyle." While Frank highlighted how alcohol could act as an accelerant for minor disrespects or disagreements "somebody more drunker than you step on your shoe, bump you a couple a times, you tell 'em to chill out, and then they wanna get ignorant, you know, and that's when a lot of the violence happens, you know, when words turn into actions.”

While serious personal victimization was prolific across narratives, also commonly discussed were instances of property crime victimization. Several respondents indicated having been "ripped off" or sold bad or fake drugs. Philip indicated that he had been "ganked" out of \$700 when he attempted to purchase cocaine to sell, but instead was sold "a bag of bakin' soda and wax." Kenny indicated that "getting bad stuff” was nothing more than a "complication" while Philip similarly reiterated that it “[came] with the territory.” Two respondents also indicated that they had been given counterfeit money during drug transactions or had been a victim of theft without force. Taylor noted that "people give you bad money... well when you're 
outside on the corner at night time, you know somebody hand you some money, you just put it in your pocket.” Sean regaled how a “dude pulled a disappearin’ act on me. I dropped stones [crack cocaine] in his hand and he asked where it went. And I'm like 'No, gimme my money, man.' and he took off runnin'." While instances of property victimization were discussed, it is likely that property victimization was underreported in the sample as interview time was monopolized by respondents discussing experiences with violent crime victimization.

Serious vicarious victimization was also raised by a few respondents when discussing experiences with victimization. Frank spoke generally about how "a lot of my friends was getting killed, lot of close people was gettin’ killed due to the fact of drug deals and you know street gang violence and stuff like that.” When asked if he was a victim of crime, Harris replied "Yes...um, the mother of my child, while she was pregnant with my son, she got shot two different cases. First time, she got shot in her face; second time, she got shot four times on different parts of her body...because of the area that I was dealing drugs in. Like gang violence.” Typifying the emotional effect of vicarious victimization, Anton recounted the fatal shooting of his childhood best friend:

I lost a loved one. Soon as I got outta jail...I was sitting in the car with him in front of his mother house. Talking to him, my best friend I grew up with. I had just gotta jail. And, and just so happen another car had drove down the street... and the car came up and came real close to his car and just shot him in the face. And he died in my arms. I'm in the car with him. I'm scared myself 'cause I've been shot in my head. But, just seeing him, my best friend die...I be having big nightmares for over this stuff. 'Cause he die right in my arms. His eyes was open, I...just his eyes. I push his [mimes closing the eyes of his friend with his hand] kinda close his eyes down and stuff like...And then, and then when they shot him, shot him in the face. I thought they fitting to come and get out the car and come around there and get me and something like that. But, thank the Lord though, they didn't though. They just got him and did the shooting him and they left. I'm like, man. 
These unprompted narratives suggest that serious vicarious victimizations can be as emotionally powerful to respondents as direct victimization experiences. Given the extent of victimization in the present sample, what needs to be addressed is whether these experiences are related to perceived behavioral change and whether victimization is identified by respondents as the catalyst for any change. Moreover, the variety of victimizations discussed affords a unique opportunity to explore whether the nature of victimization - victimization type, severity, and attribution of event to individual at-risk behavior - can account for any variation in effects on subsequent behavior.

\section{Perceived Effects of Victimization}

Table 2 shows that the majority of respondents (18 or 67\%) discussed some change in behavior subsequent to victimization. ${ }^{8}$ Almost half of the subjects discussed some change in behavior in response to victimization and recognized victimization as the catalyst of the change (13 or 48\%). A number of respondents were more conflicted (5 or 19\%) - having directly responded that they perceived that their behavior did not change subsequent to victimization, but then proceeding to discuss how their victimization experience(s) changed the ways in which they managed risks in their daily lives. Finally, many respondents discussed no changes in behavior subsequent to victimization (9 or $33 \%$ ).

\section{--INSERT TABLE 2 ABOUT HERE--}

\section{Identified Behavioral Change}

For almost half of the respondents, victimization was associated with self-identified behavioral changes. This is consistent with the assertion that victimization can provide a unique

\footnotetext{
${ }^{8}$ While 30 respondents reported some victimization experience, three cases (Anton, James, and Eric) were excluded from subsequent analysis because the effects of victimization are unknown. This is because the questions addressing the perceived effect of victimization were either misinterpreted by the subject or were not asked by the field researchers. Close inspection of these respondents' accounts of their victimization experiences indicated that they were not substantively related to their individual behavior.
} 
opportunity for individuals to reevaluate and modify their behavior. A number of respondents reported that victimization experiences led to greater use of risk minimization strategies or techniques. Respondents perceived that the application of these techniques, following a victimization episode, mitigated some of the risks associated with continued involvement in a substance using or at-risk lifestyle. Several men discussed moving away from buying or selling drugs in the open-air street market. Larry explained the risk of using an unknown street dealer, “you meet this person standing around on the street....they're lookin’ for trouble. So, you don't mess with them type of people.” To mitigate this risk, he said he would use a "person that's alright, then that's who you mess with.” Similarly, Orlando noted that "after that [robbery victimization] I just go by phone call...it changed my pattern of drug use to where...I'd go the distance...I'd get a bike and ride, two, three miles, four miles just to meet” a trusted dealer. Those who had been selling drugs also sought to deal with a restricted group of better-known clients or get out of the open-air drug market entirely. Frank explained how "some people would, um, sell to people they don't know.....which when you do that you gotta take the risk of them being an undercover cop or somebody settin' you up. I knew my customers.” Having also been a victim of a robbery, Maurice also explained: "Instead of me just like standing out on the block and selling where anybody could have access to me, I had my phone number - my phone number was given out to certain people, and I would just wait on them to call. Then, I would just go and holla at them.”

In the interest of working with a small group of clients and getting off the street, Kenny "used to just, like, stay up in the crib, in the house [to sell drugs].” While Kenny would switch to selling from his house to minimize some of the risks of dealing on the streets, he, however, perceived street dealing as somewhat safer. He explains that: 
It's harder [selling from his home] because you can't see nothing coming. You don't know when nobody going to kick your door in. You don't know who's just standing off side, just waiting for you to come. That, that, that why I think [street dealing] safer to me. See when you be out there you can see, you can see every car pass you. You know, you can see all the little gang waves and cuts.

While this is conflicting with his assertions on the safety of dealing from his home, he discussed having temporarily dealt from his home as an alternative to carrying a firearm while dealing in the streets. He notes: “I didn't really [like to] carry 'em [a handgun] around. First off they're too heavy.... Then you know, us Black men, we like to sag [our pants]....You can't, like, really run or nothing [with a gun in your pants].” Despite finding street dealing preferable, Kenny's temporary drug dealing from his home was perceived as striking a balance between avoiding the risk of open-air street dealing and the inconvenience of carrying a handgun while dealing.

Other respondents indicated the implementation a variety of other risk minimization techniques for buying and selling drugs after being victimized. Darnell noted switching dealers when he felt he was being sold bad or stretched drugs, he said: "because he [his dealer] start putting salt in the game, now, so I'll switch up.” After having been robbed, Gary noted: "I would have a lot of people around me” when buying or selling. Taylor perceived he could forestall the risk of being given counterfeit money again by "always check[ing] to make sure what I am putting in my pocket.” Moreover, he perceived that having "people I would give something [drugs or money] to let me know what's going on in the street, who's talking about me, who set me up” would help him identify and forestall personal and property victimization threats.

A number of other respondents identified that victimization had lead to a greater use of risk avoidance techniques. Orlando would avoid buying drugs in "neighborhoods where if I didn’t know the people or if they didn’t know me.” Larry “stopped goin' to get [drugs] myself” as his robbery victimization illustrated to him how “messin’ with drugs...[was] really, really 
dangerous, you could lose your life.” Similarly, Franklin explained how he temporarily stopped buying after being sold bad drugs: "I wouldn't wanna get them for awhile 'cause I was tired of getting ripped off. Or didn't know who to trust.”

For others, victimization facilitated avoiding conflicts or avoiding others entirely. Stanley stressed he avoided confrontations by “just walk[ing] away from it man. Be a better man and walk away from it. You know, if they say something, just walk away from it.” Nelson similarly vowed to not "get into anybody's business" as a perceived attempt to avoid possible conflicts and victimization. Gary attempted to avoid being victimized while buying and dealing by keeping a low profile where "pretty much I wouldn’t be seen [or] heard.”

A smaller number of subjects indicated that their victimization experiences inspired change in they way they thought about their current at-risk lifestyle. Stanley noted that "[getting shot] changed my pattern of thinking, like of how I was supposed to move. What choices I make.” Likewise, Frank said, “after I was shot, it was like is it worth it?...I started rethinking it because a lot of my friends was getting killed lot of close people was gettin' killed due to the fact of drug deals and you know street gang violence.” For Harris, the two shootings of the pregnant mother of his child weighed heavily on how he thought about his then lifestyle. He described that “it inspired me to wanna change, want something different.” This desire to change his behavior and lifestyle was based on how “I could've lost my son, I could've lost my family. I changed...I see how affecting my family that they had been going these different altercations.” For these three, shooting victimizations - both direct and vicarious - were perceived as having inspired change in how the men thought about their lifestyle and gradually influenced their subsequent involvement in substance using and street offending. 
For two other individuals, the experience of personal victimization was salient enough to bring about more immediate change in behavior. Larry perceived his robbery victimization as having facilitated his abrupt termination of dealing drugs, “[I] stopped tryin' to, uh, sell stuff." While the robbery victimization did not terminate his personal drug use, Larry discussed that he personally stopped going out to buy drugs and relied solely on his friends to procure drugs for him. Having been shot and severely injured while hanging out outside and smoking a blunt with his friends, Terrance similarly noted that his victimization changed "my behavior, my thinking, everything.” He asserted that having been shot yielded an absolute change in his behavior: "It really, I really just, that's when I really just stopped smoking in general...so I just stopped hanging out and everything." For both Larry and Terrance, their victimizations were perceived as salient turning point experiences which subsequently wrought seemingly abrupt termination of their at-risk lifestyles.

\section{Conflicted/Unrecognized Behavioral Change}

For a number of other respondents, victimization was discussed as having had a conflicted or unrecognized effect on subsequent behavior. While these individuals reported changes in behavior to avoid and manage the threat of future victimization, they did not directly attribute victimization as a facilitator of these perceived modifications. Jerome indicated that this was because he viewed victimization as just “part of the game... That ain’t unusual, that's no reason [to stop]." Walter reiterated this when he noted, "it was like this [victimization] part o' the lifestyle.” Other respondents simply reported without greater elaboration that they did not perceive their victimization(s) to have directly influenced their subsequent behavior.

Even though these respondents stated that victimization had no perceived effect on their behavior, discontinuities within narratives were identified as the men discussed the ways in 
which they learned from the experience(s) and subsequently managed the risks of the lifestyle. Zach, who discussed being robbed on three separate occasions, indicated that he subsequently “[didn’t] wear jewelry” as a means of keeping a low profile and being a less attractive target. He also perceived that not travelling alone and having defensive weapons nearby helped him alleviate some of the risks of sustained open-air drug dealing. He stated: "if I am riding I will have someone with me who got something on him...gotta have a gun or two on them.” Barry, who had been shot at, said that he would subsequently "only mess with certain people." William noted how he perceived his technique of "walk[ing] away...I'd leave” as having helped him avoid future conflicts inherent in his lifestyle. Similarly, Jerome would "holler at you later" when approached with a potential conflict. These narratives illustrate the conflicted nature of how respondents seemingly reacted following victimization and how they perceived victimization to have impacted their subsequent behavior.

Most indicative of this conflicted change was William who discussed being the victim of two robberies. He noted that after the first robbery he "was practically out for revenge if I found 'em." ${ }^{9}$ After suffering a second more severe robbery during which he was shot, he noted that "it practically changed my pattern of selling...I stopped selling. I stopped completely.” Having twice experienced violence in the course of involvement with drug dealing, he noted "it changed my...it made me cherish life a lot.” This also led him to subsequently avoid potential conflicts by "practically walk[ing] away." William’s narrative suggests that while victimization may be initially tolerated and may even facilitate a desire for retaliatory violence, there may be

\footnotetext{
${ }^{9}$ Prior research with active offender populations has found that retaliation is a commonly reported means of asserting street justice (Jacobs and Wright 2006). While the present study did not directly ask respondents about their use of retaliatory behavior, ten individuals discussed either the threat or use of violence in certain situations. It was commonly discussed as a technique used against drug buyers who did not make good on payment in a timely manner (Lamont, Maurice, Neal, Taylor, Victor, and William), suppliers who stretched drug supplies (Darnell and Philip), and known individuals who attempted or successfully stole drugs (Stanley and Zach). Outside of drug dealers, only Eric "whooped me a couple niggas' ass[es]" in what he perceived as both a retaliatory act and a technique to forestall the threat of future robberies by a few "little crack fiends."
} 
individual tolerance thresholds that, once crossed, can bring about recognized cognitive and behavioral changes.

\section{No Behavioral Change}

Many respondents asserted that victimization did not influence their behavior. Like those who experienced conflicted change in behavior, when asked how to they perceived to avoid conflicts Curtis plainly replied, “Couldn’t avoid ‘em.” Sean reiterated, “You can’t change the game. You gotta accept what comes to you.” Similarly, Ronald indicated that he perceived violence and victimization as though it “wasn't that, that big of a deal, I was used to stuff like that [being shot at]...I'm used to violence.”

This expressed acceptance of a certain element of violent or property crime risk was also evidenced by several respondents who were implementing some risk minimization techniques prior to their victimization. ${ }^{10}$ Ronald perceived he could avoid conflicts by not "let[ting] nobody mess wit' me, or make me just snap out, I know how to control my anger.” Philip, Isaac, and Lamont applied more general risk minimization techniques when they were buying and selling drugs. Philip perceived that by not “deal[ing] with nobody [he] don't already know” he could minimize the risk of being sold fake drugs. Isaac posited the two tenets of the drug dealing code: “It’s codes you live by like never sell where you sleep at. Never use your own.” Lamont noted “just don’t give credit out” because “nobody wants to pay for yesterday’s high.” This technique allowed him to perceive that he "keep a lot of confusion down" and avoided potential conflicts. Those who indicated no behavioral change subsequent to victimization acknowledged and discussed - in more general terms - the risks inherent in an at-risk lifestyle; but either expressed

\footnotetext{
${ }^{10}$ Inspection of the five non-victim respondents (Andrew, Dennis, Eddie, Neal, and Patrick) revealed that two individuals discussed the use of risk management techniques absent any discussed victimization. Andrew would try to remain calm during disagreements to prevent them from boiling over into violent encounters and Patrick would never give out any drugs on credit.
} 
generally fatalistic outlooks on violence in daily life or did not directly perceive a link between their reported victimization(s) and their own at-risk behavior and lifestyle.

\section{Victimization Type and Behavioral Change}

Within the present data, victimization was discussed as having had a range of perceived effects on individual behavioral change. This begs the question of whether there are patterns of change which are specific to the nature of victimization, particularly victimization type. To address this, the present study explored the perceived effects of the two most commonly discussed and serious forms of victimization (robbery and being shot or fired at) on behavioral change.

\section{--INSERT TABLE 3 ABOUT HERE--}

The most commonly discussed form of victimization in the sample was robbery, with nineteen individuals indicated having suffered one or more attempted or successful incidents. ${ }^{11}$ As Table 3 indicates, almost half of the men (9 or 47\%) reported and identified behavioral change subsequent to their victimization. Several (4 or 21\%) indicated that victimization did not change their behavior yet also reported subsequent changes in risk management. Finally, six individuals (32\%) stated and indicated no behavioral changes subsequent to victimization.

Robbery victims who experienced behavioral change had several common patterns in regard to their experiences and their employment of certain risk avoidance strategies. Of the nine robbery victims who reported subsequent changes in regard to risk management, all but one directly attributed their victimization to their drug using and selling lifestyle. ${ }^{12}$ In regard to

\footnotetext{
${ }^{11}$ Two robbery victims (James and Eric) were never asked whether their victimization changed patterns of drug use or behavior. See footnote 7 for additional information regarding their exclusion from analysis specific to behavioral change.

${ }^{12}$ Nelson was the one robbery victim who did not discuss a direct link between his victimization and his drug using and selling lifestyle. Nelson described that his robbery occurred when he was "walking home, they pulled a gun out on me, so empty my pockets - 'Here have it all'." Further questioning about what may have facilitated the robbery
} 
employment of specific risk avoidance strategies, the most apparent was avoidance of the openair markets for both buying and selling drugs (Frank, Kenny, Larry, Maurice, and Orlando). Robbery victims who experienced behavioral change also relied on a variety of other avoidance behaviors in what they perceived as attempts to forestall future victimization. This included avoiding unfamiliar neighborhoods (Orlando), never going out alone to procure drugs (Larry), and avoiding potentially volatile interpersonal conflicts (Stanley, Nelson, and Gary). These findings suggest that almost half of all robbery victims in the sample were more likely to have discussed a conscious link between their robbery victimization, their behavior, and their subsequent application of risk avoidance techniques.

For several other individuals, the perceived effect of victimization was more convoluted. These four men attributed their victimizations to their at-risk behavior, discussed changes in their subsequent management of lifestyle risks following the victimization episode, but did not directly perceive victimization as the catalyst of their subsequent changes in their behavior. Those robbery victims with conflicted or unrecognized behavioral change were most likely to subsequently apply both risk minimization and avoidance techniques as a perceived attempt to minimize future interpersonal conflicts inherent in their lifestyles. For all four respondents, victimizations yielded an increased reliance on avoidance techniques when subsequently approached with potential interpersonal conflicts. To avoid any future altercations, Jerome would "holler at you later” and William would "practically walk away...I'd leave.” Likewise, Zach would travel in groups and carry a weapon while Walter “[wouldn’t] bother nobody [and] start nothing." While these respondents did not perceive their behavior to have meaningfully changed, the fact that each could attribute their robbery victimizations to their at-risk behavior may 
explain why they all employed some form of risk management subsequent to their victimization experience. However, it is less clear why respondents did not directly acknowledge a link between victimization to their increased avoidance of interpersonal conflicts. ${ }^{13}$

For the many men who reported no actual or perceived behavioral change subsequent to their robbery victimization, whether the victimization was attributable to a drug using and offending lifestyle was again a pattern of great significance. Half of the robbery victims who experienced no behavioral change were not able to explicitly link their experience to their lifestyle. Curtis indicated how his robbery was perpetrated "by dudes just trying to make a name for theyselves. Just trying to look good, try to be the big man.” Carter indicated how he perceived that his assailant was “targeting anybody he just thought was a gangbanger.” Isaac believed that he was robbed when he was “goin' to meet a guy, and some other guy was waitin' for me.” For these three individuals, robbery victimizations were perceived to be unavoidable experiences unrelated to their individual lifestyle and behavior. Reggie, Lamont, and Victor, however, were robbed in the course of actively dealing drugs. Despite the clear potential to link their victimization to their offending behavior, the three individuals did not discuss that their victimization influenced their future behavior. The men only discussed - in general terms - how they perceived that they managed street risks throughout the entirety of their time dealing. Reggie asserted that he was “clever [and] more slicker.” Lamont stated generally that drug

\footnotetext{
${ }^{13}$ A justifiable criticism of the present study is whether risk management techniques were used absent of or prior to any discussed exposure to victimization. As demonstrated in footnote 10, only two respondents (Andrew and Patrick) articulated the use of risk minimization strategies absent of any discussed victimization. For those who answered that they had been the victim of a crime, respondents were first asked to describe what happened and were then asked whether they perceived the experience to have changed or influenced their subsequent behavior and management of problems or conflicts. While it is possible respondents could have erroneously discussed risk management strategies that were used prior to their victimization, care was taken to clearly delineate those who spoke generally about the use of risk management approaches and those who initiated a change in behavior following a victimization. This is clearly demonstrated by several respondents classified within the 'no behavioral change' group. These victimized respondents (Isaac, Lamont, Philip, Reggie, Ronald, and Victor) perceived that their experience did not influence or change their future behavior and spoke only of how they generally managed the risks inherent in their involvement in an at-risk lifestyle.
} 
dealing could lead to conflicts between buyers and sellers which is why he would never give drugs out on credit. Overall, whether or not the respondent could attribute their robbery to their own at-risk behavior was a central feature of whether the respondent perceived the experience influenced their subsequent behavior and management of lifestyle risks.

Being shot or fired at was the second most commonly recounted form of victimization in the present sample. Out of the twelve men who discussed this (see Table 3), many (5 or 42\%) reported and identified behavioral change subsequent to victimization. A couple (16\%) indicated that their victimization did not change their behavior, but subsequently reported changes in risk avoidance techniques. While five (42\%) discussed no actual or perceived behavioral changes subsequent to victimization.

Five respondents perceived that their being shot or fired at yielded subsequent behavioral change. For three of those individuals, they perceived that their shooting victimization forced them to rethink their involvement in a drug using and offending lifestyle. Both Terrance and Stanley noted their being shot changed the way they thought about their behavior. Frank's shooting led him to question whether "[selling drugs is] worth it?” For the other two respondents, their shooting victimization facilitated a need for greater risk minimization and avoidance behaviors. Kenny avoided selling in the open-air drug market and started defensive weapon carrying. Nelson attempted to avoid potential conflicts by not allowing others to get physically close to him. For these men the severity of being shot as well as the attribution of their victimization to their at-risk behavior seems to have facilitated not just behavioral change, but also cognitive changes specific to reevaluating their involvement in an at-risk lifestyle.

Only two individuals who suffered a shooting victimization discussed conflicted or unrecognized behavioral change. Barry, who was shot at over "some he said she said stuff," 
discussed that his victimization brought about a general avoidance of others. William - who was shot during the course of a robbery while out "walkin’ with my little sister" - believed that the shooting did not change his behavior; rather, it was his most "recent [robbery victimization]....[that] practically changed my pattern of selling.” After the first shooting he “was practically out for revenge.” However, William perceived that his more recent robbery victimization "made [him] cherish life a lot." Given that both individuals did not perceive that their shooting victimizations were explicitly linked to their at-risk behaviors, only the severity of the victimizations appeared to have impacted their use of risk management techniques following the violent episodes.

Finally, many shooting victims discussed no perceived change in behavior subsequent to their victimization. ${ }^{14}$ Both Carter and Ronald perceived that their victimization did not facilitate any behavioral change. This is likely because both discussed that they were targeted by their respective assailants based on perceived gang affiliation. Two other individuals were specifically targeted because of their drug dealing behavior; however, neither Reggie nor Victor discussed that their victimization influenced their behavior. Both men only discussed, in general terms, how they perceived to manage risks during their period of drug dealing. Again it appears that those individuals who are unable or unwilling to attribute their victimization to their at-risk behavior will be less likely to note actual or perceived change in subsequent behavior and management of lifestyle risks.

\section{DISCUSSION AND CONCLUSION}

\footnotetext{
${ }^{14}$ Curtis is counted as one of the five shooting victims who did not experience subsequent behavioral change. While he reported "I been robbed, I been shot at," the field researcher did not ask any follow up questions specific to the shooting victimization. Thus it is unclear whether his shooting victimization was related to his reported absence of behavioral changes.
} 
Previous research has shown that individuals who are involved in offending - particularly substance using and street offending lifestyles (Anderson 1999; Jacobs 2000; Waldorf 1973) generally experience greater risk and prevalence of victimization (Lauritsen and Laub 2007). While victimization can produce a range of actual and perceived changes in subsequent behavior (Ferraro 1995; Hindelang et al. 1978), less attention has been afforded to exploring what it is about the victimization - particularly subjective perceptions of the nature of the victimization experience - which produces varying effects on subsequent behavior.

The present study extends previous research through qualitative analysis of narrative accounts of victimization experiences and their perceived impact on subsequent behavior from a sample of at-risk urban men. The accounts illustrate widespread prevalence of victimization in a variety of forms. The majority of victimized men discussed being a victim of a personal crime, with robbery and gun-related crimes being the most prominent. These personal crimes were commonly discussed within the context of buying or selling drugs, but were also perceived to be wrought by perceptions of gang affiliation or being in the wrong place at the wrong time. While discussed less often, the risk of property victimization appeared omnipresent for those within an at-risk, street-oriented lifestyle. Despite the high risk of property crime, the present sample of men perceived it as a less worrisome form of victimization (see Jacobs 2000) - or as Kenny noted, nothing more than a "complication.” These lowered perceptions of severity and significance may help explain why this form of victimization was discussed less often than other more violent forms of victimization. Divergent from most research to date, a few respondents discussed the importance of experiences with serious vicarious victimization. This supports the notion that vicarious victimization can be perceived as an emotionally salient experience and can be an important component in at-risk behavior and lifestyle change (see also Decker and 
Lauritsen 2002). Overall, these findings largely corroborate prior research (Biernacki 1986; Decker and Lauritsen 2002; Decker and Van Winkle 1996; Jacobs 2000; Jacobs and Wright 2006; Jacques and Wright 2008; Waldorf 1973) by further illustrating an omnipresent risk and common occurrence of a range of victimizations for individuals within a substance using and diverse street offending lifestyle.

The extent of victimization experiences within the present sample allowed for further examination of the perceived effects of victimization on subsequent behavior and management of lifestyle risks. Over two-thirds of victimized men discussed some change in behavior subsequent to victimization - particularly in regard to management of risks associated with sustained involvement in an at-risk lifestyle. Of those, almost half of all respondents were cognizant of the effect of victimization on their subsequent behavior. For these men, most followed the assertion made by Hindelang and colleagues (1978) where individuals commonly changed the ways in which they did things following a victimization episode, rather than making substantial changes in what they did. The common application of risk minimization (e.g., switching to a closed or network-based drug market, traveling in groups, and weapon carrying) and avoidance techniques (e.g., avoiding strangers and interpersonal conflicts) discussed by the present sample of men illustrates the desire to alleviate some of the risks of sustaining involvement in at-risk behavior following victimization.

The findings also suggest that victimization can act as a catalyst for more substantial changes in behavior. Several individuals perceived that victimization changed the way in which they thought about their involvement in an at-risk lifestyle. Several respondents also directly attributed victimization, direct and vicarious, to both their then at-risk behavior and to their subsequent cessation of drug using and selling. These findings give further credence to the 
viability of the victimization-termination link (Jacques and Wright 2008) and importantly advance the hypothesis to include a broader definition of victimization experiences (i.e., direct and vicarious victimizations).

A number of study respondents reported changes in risk management subsequent to victimization, but did not directly perceive victimization as the catalyst of this change. These individuals commonly reported more subtle changes in the ways in which they interacted with others and managed interpersonal conflicts. While these men did not identify their victimization experience(s) as the catalyst for any subsequent changes in their behavior, the fact that the vast majority of these men attributed their victimization experience to their individual at-risk behavior appears to explain why subtle changes in their subsequent behavior were identified within narrative accounts. Only Barry, who discussed being shot at over "some he said she said stuff," was unable to attribute his victimization to his behavior. His perceived change in behavior (only selling drugs to a small group of individuals) appears to be largely in response to the severity of being shot at rather than its relation to his at-risk behavior and lifestyle.

While the majority of respondents discussed changes in behavior subsequent to victimization, roughly one-third of the victimized men reported and discussed no behavioral or risk management changes following their victimization experience(s). These individuals commonly discussed their victimization(s) in more general and fatalistic terms, suggesting that victimization was an unavoidable part of their lives - “couldn’t avoid ‘em [victimization]” Curtis stated - unrelated to their individual at-risk behavior or lifestyle. Sean reiterated, “You can’t change the game. You gotta accept what comes to you.” These men also deemphasized the salience or severity of victimization experience(s) - as Ronald noted “[victimization] wasn't that big of a deal....I'm used to violence." While these men did not completely disregard the use of 
risk management techniques (e.g., managing anger as well as buying from and selling drugs to only trusted individuals), they discuss their application prior to their victimization experiences(s). This finding corroborates the assertion that individuals who exude more fatalistic outlooks may be less likely to discuss changes in behavior following victimization, given that they perceive victimization to be unavoidable or they are unable or unwilling to directly attribute victimization to their own behavior (Anderson 1994; 1999; Brezina et al. 2009; Jacques and Wright 2008). Furthermore, the conferring of a fatalistic outlook may also be intertwined with an overarching desire to appear masculine and illustrate nerve in the face of danger (i.e., violence and victimization), often prolific within urban minority male samples (Anderson 1994; 1999; Brezina et al. 2009; Cobbina et al. 2008; Hindelang et al. 1978; Jacobs and Wright 2006; Van Dijk 1986). This finding raises further questions about whether prolonged exposure to violence may weaken or desensitize the potential effect(s) that victimization experiences may have on subsequent behavior and management of lifestyle risks.

In an attempt to better understand if patterns of behavioral change were tied to specific types of victimization, the study further explored patterns across the two most serious and commonly discussed forms of victimization. Despite their severity, the perceived effects of both robbery and shooting victimization on subsequent behavior (see Table 3) were largely consistent with overall victimization findings (see Table 2). Roughly two-thirds of robbery victims and the majority of shooting victims discussed some form of perceived change in behavior following victimization while many noted no change in behavior. The increased severity of victimization was, however, related to respondents discussing more substantive changes in subsequent behavior (i.e., changes in thinking about at-risk lifestyle as well as cessation of drug use or dealing). While victimization severity increased the substantive nature of perceived changes in 
subsequent behavior, the foremost factor remained whether the respondent attributed the victimization experience to his involvement in offending behavior or an at-risk lifestyle. Within the present sample, every robbery and shooting victim who perceived their victimization to be related to their at-risk behavior discussed some change in behavior following the episode.

It is important to note that the present study is not without limitations. Foremost, the sampling design employed does not allow for generalizable findings. Given the urban, all male, and overwhelmingly African-American composition of the sample, future research would benefit from exploration of whether changes in behavior and risk management subsequent to victimization differs across racial/ethnic groups, is gendered, or is influenced by community context. Moreover, as the data for this study came out of a larger project on drug use, crime, and the challenges to recovery and reintegration, it was not possible to exhaustively explore victimization histories as well as their perceived effects on subsequent behavior. Future research should attempt to more closely explore the differences between single victimization experiences and cumulative victimization histories on changes in at-risk behavior and lifestyle.

Overall, this research provides greater insight into the nature of victimization, the opportunities victimization affords for changes in subsequent behavior, as well as what contributes to the varying perceived effects of victimization on at-risk behavior, lifestyle, and management of risk. For most, victimization served as a catalyst for subtle changes in the ways in which the risks of sustained involvement in at-risk behavior were perceived to be managed. While increasing victimization severity was related to more substantive change in individual behavior, the present research demonstrates that it is the individual's attribution of their victimization(s) to their own at-risk behavior which best predicts subsequent change in behavior or lifestyle. The findings substantiate the victimization-termination hypothesis within an at-risk 
sample of urban men (Jacques and Wright 2008) as well as further demonstrates the need for a broader definition of victimization (i.e., direct and vicarious) within the hypothesis. This was demonstrated by those men who perceived the violent victimization of a friend or family member as the product of their own at-risk behavior and lifestyle. Only those individuals who exhibited a fatalistic outlook or were unable or unwilling to draw a logical connection between their victimization and behavior were justifiably unlikely to modify their future behavior, at-risk or otherwise. While victimization can afford opportunities for subtle to substantive change in an individual's behavior, lifestyle, and subsequent management of risk, this research demonstrates that it is whether the experience is perceived to be an avoidable consequence of individual at-risk behavior which best accounts for victimization's varying effects found within and across individuals in this and possibly other research. Thus while victimization has the potential to serve as a triggering event in the process of desistance from at-risk behavior, it is the nature of the victimization experience (i.e., shocking and severe as well as an avoidable product of individual at-risk behavior) on which its importance and variability is predicated on. 


\section{REFERENCES}

Adler, Patricia A. 1993. Wheeling and Dealing: An Ethnography of an Upper-Level Drug Dealing and Smuggling Community. New York: Columbia University Press.

Agnew, Robert. 2006. “Storylines as a Neglected Cause for Crime.” Journal of Research in Crime and Delinquency 43: 119-147.

Anderson, Elijah. 1994. “The Code of the Street.” Atlantic Monthly 273: 81-94.

Anderson, Elijah. 1999. Code of the Street: Decency, Violence, and the Moral Life of the Inner City. New York: Norton.

Averdijk, Margit. 2010. Individuals’ victimization patterns over time. Unpublished doctoral dissertation, Amsterdam, Netherlands: VU University Amsterdam.

Averdijk, Margit. 2011. "Reciprocal Effects of Victimization and Routine Activities.” Journal of Quantitative Criminology 27: 122-149.

Biernacki, Patrick. 1986. Pathways from Heroin Addiction: Recovery from Treatment. Philadelphia, PA: Temple University Press.

Brezina, Timothy, Tekin, Erdal, and Volkan Topalli. 2009. "Might Not Be a Tomorrow: A Multimethods Approach to Anticipated Early Death and Youth Crime.” Criminology 47: 1091-1129.

Charmez, Kathy. 2006. Constructing Grounded Theory: A Practical Guide Through Qualitative Analysis. Thousand Oaks, CA: Sage Publications.

Clarke, Ronald V. 1999 Hot Products: understanding, anticipating and reducing demand for stolen goods. London: Home Office.

Cobbina, Jennifer E., Miller, Jody, and Rod K. Brunson. 2008. “Gender, Neighborhood Danger, and Risk-Avoidance Strategies Among Urban African-American Youths.” Criminology 43: 673-703.

Cohen, Lawrence E., and Marcus Felson. 1979. "Social Change and Crime Rate Trends: A Routine Activity Approach.” American Sociological Review 44: 488-608.

Cusson, Maurice, and Pierre Pinsonneault. 1986. “The Decision to Give Up Crime.” Pp. 72-82 in The Reasoning Criminal: Rational Choice Perspectives on Criminal Offending, edited by Derek Cornish and Ronald Clarke. New York: Springer.

Decker, Scott H., and Janet L. Lauritsen. 2002. “Leaving the Gang.” Pp. 51-67 in Gangs in America, edited by C. Ronald Huff. Thousand Oaks, CA: Sage Publications.

Decker, Scott H., and Barrik Van Winkle. 1996. Life in the Gang: Family, Friends, and Violence. New York: Cambridge University Press.

Esbensen, Finn-Aage, and David Huizinga. 1991. "Juvenile Victimization and Delinquency. Youth and Society 23: 202-228.

Fagan, Jeffrey A. and Angela Browne. 1994. "Violence Between Spouses and Intimates: Physical Aggression Between Women and Men in Intimate Relationships." Pp. 115-292 in Understanding and Preventing Violence, Volume 3 Social Influences, edited by Albert J. Reiss, Jr. and Jeffrey A. Ross. Washington, D.C.: National Academy Press.

Ferraro, Kenneth F. 1995. Fear of Crime: Interpreting Victimization Risk. New York: State University of New York Press.

Garofalo, James. 1979. “Victimization and the Fear of Crime.” Journal of Research in Crime and Delinquency 16: 80-97.

Glaser, Barry, and Anselm Strauss. 1967. The Discovery of Grounded Theory. Chicago: Aldine. 
Gottfredson, Michael. 1984. Victims of Crime: The Dimensions of Risk. Home Office Research Study No. 81. London: Her Majesty's Stationery Office.

Hindelang, Michael J., Gottfredson, Michael R., and James Garofalo. 1978. Victims of Personal Crime: An Empirical Foundation for a Theory of Personal Victimization. Cambridge, MA: Ballinger Publishing Company.

Jacobs, Bruce A. 1999. Dealing Crack: The Social World of Streetcorner Selling. Boston: Northeastern University Press.

Jacobs, Bruce A. 2000. Robbing Drug Dealers: Violence Beyond the Law. New York: Aldine De Gruyter.

Jacobs, Bruce A., and Richard Wright. 2006. Street Justice: Retaliation in the Criminal Underworld. New York: Cambridge University Press.

Jacques, Scott, and Danielle M. Reynald. 2012. "The Offenders' Perspective on Prevention: Guarding Against Victimization and Law Enforcement.” Journal of Research in Crime and Delinquency 49: 269-294.

Jacques, Scott, and Richard Wright. 2008. “The Victimization-Termination Link.” Criminology 46: 501-530.

Jensen, Gary, and David Brownfield. 1986. “Gender, Lifestyles, and Victimization: Beyond Routine Activity.” Violence and Victims 1: 85-99.

Lauritsen, Janet L., and John H. Laub. 2007. "Understanding the Link Between Victimization and Offending: New Reflections on an Old Idea." Crime Prevention Studies 2: 55-76.

Lauritsen, Janet L., Sampson, Rob, and John H. Laub. 1991. "The Link Between Offending and Victimization Among Adolescents.” Criminology 29: 265-292.

Mayhew, Pat. 1993. "Measuring the Effects of Crime in Victimization Surveys.” Pp. 187-200 in Fear of Crime and Criminal Victimization, edited by Wolfgang Bilsky et al. Stuttgard: Ferdinand Enke.

Melde, Chris. 2009. "Lifestyle, Rational Choice, and Adolescent Fear: A Test of a RiskAssessment Framework.” Criminology 47: 781-811.

Miethe, Terance D., and Robert F. Meier.1994. Crime and Its Social Context: Toward an Integrated Theory of Offenders, Victims, and Situations. Albany, NY: State University of New York Press.

Miller, Jody. 2005. “The Status of Qualitative Research in Criminology.” Pp. 69-75 in Workshop on Interdisciplinary Standards for Systematic Qualitative Research: Cultural Anthropology, Law and Social Science, Political Science, and Sociology Programs. Arlington, VA: National Science Foundation.

Miller, Jody. 2011. "Grounding the Analysis of Gender and Crime: Accomplishing and Interpreting Qualitative Interview Research.” Pp. 49-62 in The Sage Handbook of Criminological Research Methods, edited by David Gadd et al. Thousand Oaks, CA: Sage Publications.

Ousey, Graham C., Wilcox, Pamela, and Bonnie S. Fisher. 2011. "Something Old, Something New: Revisiting Competing Hypotheses of the Victimization-Offending Relationship Among Adolescents.” Journal of Quantitative Criminology 27: 53-84.

Roberts, Jennifer J., and Julie Horney. 2010. “The Life Event Calendar Method in Criminological Research.” Pp. 289-312 in Handbook of Quantitative Criminology, edited by Alex Piquero and David Weisburd. New York: Springer.

Rosenfeld, Richard., Jacobs, Bruce A., and Richard Wright. 2003. "Snitching and the Code of the Street.” British Journal of Criminology 43: 291-309. 
Sampson, Robert, and Janet L. Lauritsen. 1990. "Deviant Lifestyles, Proximity to Crime, and the Offender-Victim Link in Personal Violence.” Journal of Research in Crime and Delinquency 27: 110-139.

Shover, Neal. 1996. Great Pretenders: Pursuits and Careers of Persistent Thieves. Boulder, CO: Westview Press.

Silverman, David. 2006. Interpreting Qualitative Data. Thousand Oaks, CA: Sage Publications.

Skogan, Wesley G. 1981. "On Attitudes and Behaviors.” Pp. 19-45 in Reactions to Crime, Volume 16, edited Dan A. Lewis. Beverly Hills, CA: Sage Publications.

Skogan, Wesley G., and Michael G. Maxfield. 1981. Coping with Crime: Individual and Neighborhood Reactions. Beverly Hills, CA: Sage Publications.

Spradley, James P. 1979. The Ethnographic Interview. Belmont, CA: Wadsworth Group. Sutherland, Edwin. 1937. The Professional Thief. Chicago: University of Chicago Press.

Van Dijk, Jan. 1986. "Responding to Crime: Reflections on the Reaction of Victims and NonVictims to the Increase in Petty Crime.” Pp 156-166 in From Crime Policy to Victim Policy: Reorienting the Justice System, edited by Ezzat A. Fattah. New York: St. Martin's Press.

Waldorf, Dan. 1973. Careers in Dope. Englewood Cliffs: Prentice-Hall.

Widom, Cathy S. 1989a. "Does Violence Beget Violence? A Critical Examination of the Literature.” Psychological Bulletin 106: 3-28.

Widom, Cathy S. 1989b. “The Cycle of Violence.” Science 244: 160-166. 
Table 1. Nature of Victimization $(\mathrm{N}=30)$

Number of Victimizations Discussed by Individuals One Victimization

$13(43 \%)$

Two or More Victimizations

17 (57\%)

Nature of Specific Victimization

Personal

Robbery

$25(83 \%)$

Shot

$21(70 \%)$

Shot at

7 (23\%)

Simple/Aggravated Assault

6 (20\%)

Property

Sold Fake/Bad Drugs

$3(10 \%)$

7 (23\%)

Theft of Drugs or Counterfeit Money

$4(13 \%)$

2 (7\%)

Serious Vicarious Victimization

$3(10 \%)$ 
Table 2. Perceived Effects of Victimization $(\mathrm{N}=27)$

Identified behavioral change

$13(48 \%)$

Conflicted/unrecognized behavioral change

No behavioral change

$5(19 \%)$

$9(33 \%)$ 
Table 3. Victimization Type and Behavioral Change

$\begin{array}{lll}\text { Robbery Victimization }(\mathrm{N}=19) & & \\ \text { Identified behavioral change } & 9 & (47 \%) \\ \text { Conflicted/unrecognized behavioral change } & 4 & (21 \%) \\ \text { No behavioral change } & 6 & (32 \%)\end{array}$

Shooting Victimization $(\mathrm{N}=12)$

Identified behavioral change $\quad 5$ (42\%)

Conflicted/unrecognized behavioral change $\quad 2$ (16\%)

No behavioral change

5 (42\%) 